\title{
Considering Risk Associated with the Realization of Waste Management Investment Plans in Cracow
}

\author{
Gabriela Hajduga ${ }^{1, *}$, and Agnieszka Generowicz ${ }^{1}$ \\ ${ }^{1}$ Cracow University of Technology, Department of Environmental Engineering, Institute of Water \\ Supply and Environmental Protection, 24 Warszawska, 30-155 Cracow, Poland
}

\begin{abstract}
To fulfill obligations to the European Union on waste management, the authorities of the city of Cracow, decided to build a waste incineration plant. Such investment involves considerable risks, not only financial but also social. The paper conducted a risk analysis based on the index net present value, identifies factors which are particularly exposed, and proposes solutions for reducing its level.
\end{abstract}

\section{Introduction}

Poland was obligated by the European Union, to implement regulations relating to environmental protection including solid waste management. The main legal act which controls the matter of municipal solid waste management is the Directive 2008/98/EC of the European Parliament and of the Council of 19 November 2008 on waste. It establishes major principles such as an obligation to handle waste in a way that doesn't have a negative impact on the environment or human health, an encouragement to apply the waste hierarchy and, implying application of the polluter-pays principle. In connection with new laws, every city in Poland, including Cracow, started intensified preparatory work for implementation of a modern waste management system. City government hired a group of specialist from the fields such as law, environmental protection and economics to create a few system solutions and recommend the best one. The result of their work was descriptive assessment titled "Evaluation of the Strategic Waste Management System of the City of Krakow", which is the main source of information in this article. Recommendation for implementation got the scenario, which includes an investment of a waste incineration plant. This article shows aspects which was taken into account in multi-criteria assessment conducted to emerge the best scenario and because this was the high-risk investment, also factors, that could have the highest impact, were identified and analyzed. For the purpose of this analysis the value of the net present value (NPV) was determined, which was used to carry out the sensitivity and scenario analysis, which culminated in a qualitative risk assessment $[1,2]$. The aim of the article, was to present the assumptions of sensitivity analysis of the scenarios for management of waste system on the example of Cracow.

\footnotetext{
*Corresponding author: gabriela.hajduga@gmail.com
} 


\section{Scenarios for the development of waste management system in the city of Cracow}

In created "Evaluation of...", four different scenarios of development of municipal waste management system were analyzed. Scenario S0 required expansion of the system for another landfill however, since 2013 it would not meet the legal requirements, therefore it was rejected. Scenario S1 not only required a new landfill, but also included creating subsequent lines in waste sorting plant, expansion of municipal solid waste composting plant, and new mechanical biological treatment plant of municipal waste. In addition, the implementation of this scenario required a large financial outlays on environmental education and the development of waste segregation "at source". Assumptions of scenario S2 largely are consistent with scenario S1, but in each of these variants, all abovementioned investments have different capacities (can process different volumes of the waste stream). Scenario S3 was the most innovative one. Except of elements from other scenarios, it included a new investment, which was incineration plant with possibility of energy and heat recovery, a solution not commonly used in Poland [1, 3, 4].

Creating each well-functioning system of waste management, requires a detailed analyzes of factors such as: the expected amount of waste, used technology, economic opportunities and social attitudes, therefore, the final selection should never be guided by only one criterion, but every possible scenario should be evaluated. In Cracow, a multicriteria analysis was conducted of all the proposed solutions, which includes 11 of the most important criteria divided into three groups (Table 1). For multi-criteria analysis, the compromise programming method was applied, which uses the concept of ordering individual strategies according to their distance from the established ideal point (Equation 1). The equation determines the value of the criterion that aggregates the distance measure of the studied strategy from the ideal point, while choosing the best strategy is based on the Equation 2. In calculations it was accepted, the limitation of the so-called acceptance threshold (Equation 3), which is a solution to the decision-making problem, ie, strategies that are ideally close to the ideal point marked in the result table by the symbol *. The method consists in finding the best strategy which takes into account all the mentioned above criteria. For the calculation it was necessary to create a hierarchy of all criteria defining the priorities of the participants in the decision making process. The criteria weights were adopted according to the authors of "Evaluation of...", as shown in Table 2. The criteria were organized into three groups, so subsequent numbers indicate the weight of individual criteria groups. In the first line, all the criteria are equivalent, in second one, the first group has assigned weight equals 5 while the others 1 and so on. The analysis results are shown in Table 2 [3, 5-7].

$$
\begin{gathered}
L_{\alpha}\left(s_{n}\right)=\sum_{m=1}^{M} w_{m}^{\alpha} \cdot\left(x_{m}^{\prime}-r_{N M}^{\prime}\right)^{\alpha} \\
s_{j}=\bar{s} \Leftrightarrow L_{\alpha}\left(s_{j}\right)=\min L_{\alpha}\left(s_{j}\right) ; n=1,2, \ldots \\
s_{n}=0,1 \cdot L_{\alpha}\left(s_{n}\right)_{\min }
\end{gathered}
$$

$L_{\alpha}\left(s_{n}\right)$ - distance measure of the studied strategy $s_{n}$ from the ideal point, $\bar{s}$ - chosen strategy, $w_{m}$ - weight factor of criterion m, $x_{m}-\mathrm{m}$-coordinates of utopian point, $r_{N M}$ - normalized value of the criterion, $M$ - number of criteria, $\alpha$ - an exponent, measuring the deviation of the strategy from the utopian point. 
Table 1. Classification and description of the criteria evaluated in choosing the best scenario [4].

\begin{tabular}{|c|c|c|}
\hline CRITERIA & SYMBOI & NAME OF CRITERION \\
\hline \multirow{5}{*}{$\begin{array}{l}\text { Minimization and } \\
\text { recovery of waste }\end{array}$} & K1 & Reduction of landfill waste. \\
\hline & $\mathrm{K} 2$ & Reducing the amount of landfilled biodegradable waste. \\
\hline & K3 & The recovery of secondary raw materials. \\
\hline & K4 & Energy recovery. \\
\hline & K5 & Exploitation time of the landfill. \\
\hline \multirow{4}{*}{ Socio-political } & K6 & $\begin{array}{l}\text { Compliance with the conditions set by the National Waste } \\
\text { Management Plan, etc. }\end{array}$ \\
\hline & K7 & $\begin{array}{l}\text { Compliance with EU and Polish law for the protection of the } \\
\text { environment. }\end{array}$ \\
\hline & K8 & Regionality and prospectivity solutions. \\
\hline & K9 & $\begin{array}{l}\text { Social acceptance. In Poland this is a highly controversial } \\
\text { investment. People aren't aware of safety and benefits of building } \\
\text { this investment. }\end{array}$ \\
\hline \multirow{2}{*}{ Economic } & K10 & Monthly financial charge per capita. \\
\hline & K11 & The cost of 1 ton of waste disposal. \\
\hline
\end{tabular}

Table 2. The results of multi-criteria analysis to choose the best scenario for the waste management system for the City of Cracow [4].

\begin{tabular}{|c|c|c|c|}
\hline \multirow{2}{*}{$\begin{array}{c}\text { Hierarchy of precedence } \\
\text { (in order from Table 1) }\end{array}$} & \multicolumn{3}{|c|}{ LINEUP OF STRATEGY } \\
\cline { 2 - 4 } & alpha $=\mathbf{1}$ & alpha $=\mathbf{2}$ & alpha $=\infty$ \\
\hline $1: 1: 1$ & $\mathrm{~S} 3^{*} \rightarrow \mathrm{S} 2 \rightarrow \mathrm{S} 1 \rightarrow \mathrm{S} 0$ & $\mathrm{~S} 3^{*} \rightarrow \mathrm{S} 1 \rightarrow \mathrm{S} 2 \rightarrow \mathrm{S} 0$ & $\mathrm{~S} 3^{*} \rightarrow \mathrm{S} 2 \rightarrow \mathrm{S} 1 \rightarrow \mathrm{S} 0$ \\
\hline $5: 1: 1$ & $\mathrm{~S} 3^{*} \rightarrow \mathrm{S} 1 \rightarrow \mathrm{S} 1 \rightarrow \mathrm{S} 0$ & $\mathrm{~S} 3^{*} \rightarrow \mathrm{S} 2 \rightarrow \mathrm{S} 1 \rightarrow \mathrm{S} 0$ & $\mathrm{~S} 3^{*}$ \\
\hline $10: 1: 1$ & $\mathrm{~S} 3^{*} \rightarrow \mathrm{S} 2 \rightarrow \mathrm{S} 1 \rightarrow \mathrm{S} 0$ & $\mathrm{~S} 3^{*} \rightarrow \mathrm{S} 2 \rightarrow \mathrm{S} 1 \rightarrow \mathrm{S} 0$ & $\mathrm{~S} 3^{*}$ \\
\hline $1: 5: 1$ & $\mathrm{~S} 3^{*} \rightarrow \mathrm{S} 2 \rightarrow \mathrm{S} 1 \rightarrow \mathrm{S} 0$ & $\mathrm{~S} 3^{*} \rightarrow \mathrm{S} 1 \rightarrow \mathrm{S} 2 \rightarrow \mathrm{S} 0$ & $\mathrm{~S} 3^{*}$ \\
\hline $1: 10: 1$ & $\mathrm{~S} 3^{*} \rightarrow \mathrm{S} 2 \rightarrow \mathrm{S} 1 \rightarrow \mathrm{S} 0$ & $\mathrm{~S} 3^{*} \rightarrow \mathrm{S} 1 \rightarrow \mathrm{S} 2 \rightarrow \mathrm{S} 0$ & $\mathrm{~S}^{*}$ \\
\hline $1: 15: 1$ & $\mathrm{~S} 3^{*} \rightarrow \mathrm{S} 2 \rightarrow \mathrm{S} 1 \rightarrow \mathrm{S} 0$ & $\mathrm{~S} 3^{*} \rightarrow \mathrm{S} 1 \rightarrow \mathrm{S} 2 \rightarrow \mathrm{S} 0$ & $\mathrm{~S}^{*}$ \\
\hline $1: 1: 2$ & $\mathrm{~S} 3^{*} \rightarrow \mathrm{S} 1 \rightarrow \mathrm{S} 2 \rightarrow \mathrm{S} 0$ & $\mathrm{~S} 3^{*} \rightarrow \mathrm{S} 0 \rightarrow \mathrm{S} 1 \rightarrow \mathrm{S} 2$ & $\mathrm{~S} 3^{*}$ \\
\hline $1: 1: 5$ & $\mathrm{~S} 3^{*} \rightarrow \mathrm{S} 0 \rightarrow \mathrm{S} 1 \rightarrow \mathrm{S} 2$ & $\mathrm{~S} 3^{*} \rightarrow \mathrm{S} 0 \rightarrow \mathrm{S} 1 \rightarrow \mathrm{S} 2$ & $\mathrm{~S} 3^{*} \rightarrow \mathrm{S} 1 \rightarrow \mathrm{S} 0 \rightarrow \mathrm{S} 2$ \\
\hline $1: 1: 6$ & $\mathrm{~S} 3^{*} \rightarrow \mathrm{S} 0 \rightarrow \mathrm{S} 1 \rightarrow \mathrm{S} 2$ & $\mathrm{~S} 3^{*} \rightarrow \mathrm{S} 0 \rightarrow \mathrm{S} 1 \rightarrow \mathrm{S} 2$ & $\mathrm{~S} 3^{*} \rightarrow \mathrm{S} 1 \rightarrow \mathrm{S} 0 \rightarrow \mathrm{S} 2$ \\
\hline $1: 1: 10$ & $\mathrm{~S} 3^{*} \rightarrow \mathrm{S} 0 \rightarrow \mathrm{S} 1 \rightarrow \mathrm{S} 2$ & $\mathrm{~S} 0^{*} \rightarrow \mathrm{S} 3 \rightarrow \mathrm{S} 1 \rightarrow \mathrm{S} 2$ & $\mathrm{~S} 3^{*} \rightarrow \mathrm{S} 1 \rightarrow \mathrm{S} 0 \rightarrow \mathrm{S} 2$ \\
\hline $5: 1: 5$ & $\mathrm{~S} 3^{*} \rightarrow \mathrm{S} 0 \rightarrow \mathrm{S} 2 \rightarrow \mathrm{S} 1$ & $\mathrm{~S} 3^{*} \rightarrow \mathrm{S} 0 \rightarrow \mathrm{S} 1 \rightarrow \mathrm{S} 2$ & $\mathrm{~S} 3^{*}$ \\
\hline $1: 5: 5$ & $\mathrm{~S} 3^{*} \rightarrow \mathrm{S} 1 \rightarrow \mathrm{S} 2 \rightarrow \mathrm{S} 0$ & $\mathrm{~S} 3^{*} \rightarrow \mathrm{S} 1 \rightarrow \mathrm{S} 2 \rightarrow \mathrm{S} 0$ & $\mathrm{~S} 3^{*}$ \\
\hline $5: 5: 1$ & $\mathrm{~S} 3^{*} \rightarrow \mathrm{S} 2 \rightarrow \mathrm{S} 1 \rightarrow \mathrm{S} 0$ & $\mathrm{~S} 3^{*} \rightarrow \mathrm{S} 2 \rightarrow \mathrm{S} 1 \rightarrow \mathrm{S} 0$ & $\mathrm{~S} 3^{*}$ \\
\hline
\end{tabular}

\section{Risk analysis}

In the discipline of engineering and environmental protection, there are a variety of definitions of risk, but in the case of investments, the risks is associated with obtaining the benefits other than expected, ie. higher or lower, or in time and period other than planned. Making economic decisions it should be taken into account the risks associated with the danger of not achieving the intended purpose, in turn, failure to achieve the objective pursued may be associated not only with the occurrence of the loss, but also obtaining a result lower than expected $[1,8,9]$.

\subsection{Financial analysis}

As it was already mentioned, the variant recommended for the implementation, was scenario in which, the investment of the incineration plant was planned therefore, only that scenario was analyzed. This object is a financial challenge and socially controversial. Investments of this type are classified, as large projects that could get financial support from the UE. However, they require analyzes, which is always evaluated by experts. This 
assessment concerns economic factors, environmental impacts (pollution reduction), social (creation of new jobs), and risk assessment. That is why it was possible to use the guidelines contained in the "Guide to Cost-Benefit Analysis of Investment Projects". According to the guide, the risk analysis should begin, by determining the net present value (NPV), which is used to estimate the cumulative net benefits of the investment project (Equation 4). It express the difference between the actual current cash inflows and outflows and it takes into account the changing value of money over time $[8,10,11]$.

$$
N P V=\sum_{t=1}^{n} \frac{B_{t}-C_{t}}{(1+i)^{n}}-I_{0}
$$

$B_{t}$ - revenues in t year t [zł], $C_{t}$ - costs in t years [zł], $i$ - discount rate [\%] - adopted at the level of $6 \%$, $n$ - the life of the investment object [years] - adopted 25 years, $\mathrm{I}_{0}$ - investment costs [zł], $\mathrm{B}_{\mathrm{t}}-\mathrm{N}_{\mathrm{t}}=\mathrm{NFC}-$ net cash flow $[\mathrm{zt}]$.

According to the given information, the income earned by incineration plant include revenues for accepting waste, from the sale of heat, electricity and residents charges. Their value depends on the number of inhabitants, tariff rates and the quantity and quality of the treated waste, but such particulars data have not been available for analysis. Using the formula 4 , it was possible to determine the values of NPV, which for this case amounted to $-594609624 \mathrm{zl}$, and also the discounted cash inflows (Figure 1). Theoretically, investments for which NPV $<0$, should not be implemented, because they bring more losses than benefits, but in the case of investment of public benefit, qualifies the project to obtain subsidies from the EU $[8,9,12]$. In addition, Figure 1 shows that the difference between spending and revenues will decrease systematically and so after 25 years will be $75.5 \%$ lower than at the beginning, because even the costs will increase, revenues also obtain higher rate.

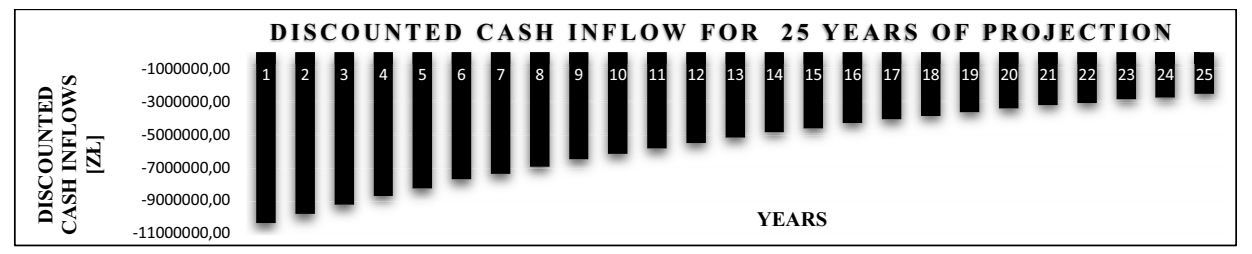

Fig. 1. Discounted cash inflow (source: own elaboration).

\subsection{Sensitivity analysis}

The sensitivity analysis consists in determining the impact of changes in individual variables, critical to the NPV value. The critical variables are identified as those, where the change in their value of $+/-1 \%$ compared to the baseline scenario, may change the value of the NPV index, according to the adopted criterion (+-/ 1\% NPV). The analysis allows to determine the critical variables of incineration plant project. These changes can be positive or negative. The studied variables should be independent and deterministic as the most disaggregated. In the present case, such detailed data were not available, so changes were made in general values of discount rate, investment costs, operating costs and revenues (Table 3) $[8,10,12,13]$.

The analysis shows, that the investment is most sensitive to the change of the discount rate. Note however, its level was adopted on the basis of the recommendations of the EU. In fact, the adoption of the discount rate is highly subjective and moreover, it can change over time and depends on the rate of inflation. Therefore, in this case, should be consider the overall effect of changes in the discount rate, rather than specific values. In the case of 
manipulating the value of investment expenditures, changing their values has relatively little impact on the deviation of NPV. However, it should be noted, that the funding of this type of investment ranged from 30 to $60 \%$ of the cost, therefore so significant change of those costs would have much more significant impact on final result of NPV. Considering the increase/decrease of operating costs and revenues, in both cases it is shown that the change causes min $1.5 \%$ change in the NPV value. Therefore, in the later stages of risk analysis, should pay attention to the factors that affect their values.

Table 3. The results of the sensitivity analysis (source: own elaboration).

\begin{tabular}{|c|c|c|c|}
\hline \multicolumn{2}{|c|}{ Variable } & $\mathbf{- 1 \%}$ of the variable & $\mathbf{+ 1 \%}$ of the variable \\
\hline \multirow{2}{*}{ Discount rate } & NPV & $-592779908 \mathrm{zl}$ & $-569809704 \mathrm{zl}$ \\
\cline { 2 - 4 } & Change of NPV & $2,07 \%$ & $1,84 \%$ \\
\hline \multirow{2}{*}{ Investment costs } & NPV & $-575966063 \mathrm{zl}$ & $-585030496 \mathrm{zl}$ \\
\cline { 2 - 4 } & Change of NPV & $0,78 \%$ & $0,78 \%$ \\
\hline \multirow{2}{*}{ Operating costs } & NPV & $-570563438 \mathrm{zl}$ & $-590433106 \mathrm{zl}$ \\
\cline { 2 - 4 } & Change of NPV & $2,0 \%$ & $2,0 \%$ \\
\hline \multirow{2}{*}{ Revenues } & NPV & $-589160348 \mathrm{zl}$ & $-571836212 \mathrm{zl}$ \\
\cline { 2 - 4 } & Change of NPV & $1,49 \%$ & $1,49 \%$ \\
\hline
\end{tabular}

\subsection{Scenario analysis}

In the first step of this method, authors had to specify three variants of the investment. The first of these - a base scenario, which does not introduce any changes. Due to the fact that the investment of a waste incineration plant is a project applying for obtaining grants (The EU has enabled obtaining grant funds only for combustion installations), other variants will vary in amount of subsidies. The amount of the grant could range from $30-60 \%$ of the cost. The second embodiment will refer to the possibility of obtaining $30 \%$ subsidy, and the third - $60 \%$. For adopted variants, the values of NPV should be determined and then, each of the scenarios is credited with the probability of occurrence. Analyzing the EU subsidies in other countries, and the level of innovation introduced in the country by this project, it could be assumed, that the project will receive $30 \%$ subsidy of investment costs $[7,8,13]$. Therefore this variant should be treated as primary, which was credited with $50 \%$ the probability of occurrence. In the optimistic scenario, the grant will be awarded on the maximum level, and in pessimistic - that the project does not receive funding. These two last scenarios were credited with $25 \%$ probability of occurrence. The next step, the expected value needs to be determined $\left(E_{N P V}\right)$, which must include the probability of occurrence of each scenario (Table 4$)$. Then, the standard deviation $\left(\sigma_{N P V}\right)$ of these values was determined and coefficient of variation $C V$ on basis of Equation 5 [1].

$$
C=\frac{\sigma_{N P V}}{E_{N P V}}
$$

Table 4. The results of calculations using scenario analysis (source: own elaboration).

\begin{tabular}{|c|c|c|c|}
\cline { 2 - 4 } \multicolumn{1}{c|}{} & SCENARIO I & SCENARIO II & SCENARIO III \\
\cline { 2 - 4 } \multicolumn{1}{c|}{} & Subsidy 30\% & without subsidies & Subsidy 60\% \\
\hline NPV [z]] & -444531774 & -580498279 & -308565268 \\
\hline Percentage change of NPV [\%] & 23 & - & 47 \\
\hline SCENARIO & NPV [zl] & Probability & Probability·NPV \\
\hline Scenario I & -444531774 & 0,5 & -222265887 \\
\hline Scenario II & -580498279 & 0,25 & -145124569 \\
\hline Scenario III & -308565268 & 0,25 & -77141317 \\
\hline
\end{tabular}

Expected value: - 444531774 zł; Standard deviation: 96142838 zł; Coefficient of variation: $0.22[-]$. 
Negative NPV after taking into account the support of the EU does not mean that the project is not desirable, and the project should be canceled. It means that it does not bring a proper financial return on national capital in accordance with the applicable reference value $(6 \%)$. Such results are obtained often $[7,9]$. In these cases, the particular importance of ensuring financial sustainability of the project. Deviation NPV amounted over 96 millions zt - therefore considered investment can bring the NPV of 96 millions higher or lower in relation to the expected value which represents more than $22 \%$ of its value.

\subsection{Qualitative risk assessment}

For the investment of waste incineration plant in Cracow, because of the scale of the project and because of the lack of detailed data, authors performed qualitative risk assessment, which performed a descriptive assessment of the probability $(\mathrm{P})$, the materialization of a given factor, its severity (S) and overall, the assessment and reduction method using a risk matrix. Another object of this analysis was to determine adverse events, which may affect the project, the level of probability of their occurrence, severity of their effects and assess the level of risk, through the interpretation of a matrix consisting of an assessment of acceptable levels of risk and a description of measures to prevent or reduce risk in reference to its main types. The scale of severity has V stages, where I - is described as not impinging, and V - can have a disastrous impact on investment (Table 5). Events were credited with the probability of occurrence where $[7,9]$ :

A- Very improbable events - probability of the occurrence $0-10 \%$,

B- Improbable events - probability of the occurrence 10-33\%,

C- Events quite likely - probability of the occurrence $33-66 \%$,

D- events likely - probability of the occurrence $66-90 \%$,

E- events very likely - probability of the occurrence $90-100 \%$.

Table 5. The classification of severity of risk factors $[4,7]$.

\begin{tabular}{|c|c|}
\hline SCALE & MEANING \\
\hline I & No impact on the social well-being, despite the lack of action. \\
\hline II & $\begin{array}{c}\text { A slight loss of social well-being generated by the project, with minimal impact on its long } \\
\text { term effects. However, the effects require remedial action. }\end{array}$ \\
\hline III & $\begin{array}{l}\text { Moderate. The project causes a loss of social welfare and/or financial loss, even in the } \\
\text { medium and long term. Materialized effects can be addressed effectively. }\end{array}$ \\
\hline IV & $\begin{array}{l}\text { Critical. The project results in a significant loss of social welfare. Implementation of the } \\
\text { risk of negating the basic functions of the project. Remedial action, even very complex, } \\
\text { they are not able to compensate for the effects. }\end{array}$ \\
\hline V & $\begin{array}{c}\text { Catastrophic. Defectiveness of the project, which may result in serious or even total loss of } \\
\text { the intended function. }\end{array}$ \\
\hline
\end{tabular}

On the basis of these two qualifications it was possible to create a risk matrix, which will characterize the level of risk of a given factor - P $\cdot \mathrm{S}$ (Table 6) and further allowed to characterized those factors, that threaten the investment, rated their level and described actions to reduce them. Evaluating each of the factors was based on the experience of literature, as well as other investments in public utilities and infrastructure [7,9].

Table 6. Assessment of the level of risk P.S [4, 7].

\begin{tabular}{|c|c|c|c|c|c|c|}
\hline \multicolumn{1}{c|}{ S } & I & II & II & IV & V \\
\hline A & LOW & LOW & LOW & LOW & MODERATE \\
\cline { 2 - 7 } & $\mathbf{B}$ & LOW & LOW & MODERATE & MODERATE & HIGH \\
\cline { 2 - 7 } & $\mathbf{C}$ & LOW & MODERATE & MODERATE & HIGH & HIGH \\
\cline { 2 - 7 } & D & LOW & MODERATE & HIGH & VERY HIGH & VERY HIGH \\
\hline & E & MODERATE & HIGH & VERY HIGH & VERY HIGH & VERY HIGH \\
\hline
\end{tabular}


The results of the qualitative risk assessment are presented below on the Table 7 .

Table 7. The results of the qualitative risk assessment (source: own elaboration).

\begin{tabular}{|c|c|c|c|c|}
\hline $\begin{array}{l}\text { DESCRIPTION OF } \\
\text { RISK }\end{array}$ & $\mathbf{P}$ & $\mathbf{S}$ & $\mathbf{P} \cdot \mathbf{S}$ & PREVENTION \\
\hline \multicolumn{5}{|c|}{ RISKS AFFECTING THE DELAY IN PUTTING INTO OPERATION OF INVESTMENT } \\
\hline Loss of financial liquidity & $\mathrm{B}$ & $\mathrm{V}$ & HIGH & $\begin{array}{l}\text { The adoption of an appropriate time horizon for } \\
\text { the project, and alternative funding sources. }\end{array}$ \\
\hline $\begin{array}{l}\text { Errors in the design } \\
\text { documentation }\end{array}$ & $\mathrm{C}$ & III & MODERATE & $\begin{array}{l}\text { Realization of the project documentation by a } \\
\text { company with proper experience. }\end{array}$ \\
\hline Delays in the schedule & $\mathrm{D}$ & $\mathrm{V}$ & VERY HIGH & $\begin{array}{c}\text { Commissioned works and construction supervision } \\
\text { by experienced engineering staff. }\end{array}$ \\
\hline $\begin{array}{l}\text { Unforeseen obstacles or } \\
\text { weather conditions }\end{array}$ & $\mathrm{C}$ & IV & HIGH & $\begin{array}{l}\text { Preparation of a new geodetic maps, site visit, the } \\
\text { corresponding assumptions in the schedule. }\end{array}$ \\
\hline Social discontent & $\mathrm{D}$ & IV & VERY HIGH & $\begin{array}{l}\text { Conducting public consultation from an early } \\
\text { stage of the project by the staff of specialists. }\end{array}$ \\
\hline $\begin{array}{l}\text { Delays in the signing of the } \\
\text { contract for construction }\end{array}$ & $\mathrm{C}$ & III & MOD & $\begin{array}{l}\text { Employment of professionals. Adoption of the } \\
\text { time margin. }\end{array}$ \\
\hline \multicolumn{5}{|c|}{ RISKS FROM THE DEMAND FO SERVICES } \\
\hline $\begin{array}{c}\text { Smaller stream and the } \\
\text { calorific value of the waste } \\
\text { than expected }\end{array}$ & $\mathrm{C}$ & III & MODERATE & $\begin{array}{l}\text { The analysis should be carried out on the basis of } \\
\text { cautious assumptions about the production of } \\
\text { waste and a comparison with a similar area. }\end{array}$ \\
\hline \multicolumn{5}{|c|}{ RISK OF FINANCIAL MANAGEMENT } \\
\hline $\begin{array}{l}\text { Exceeding the investment } \\
\text { costs }\end{array}$ & $\mathrm{C}$ & III & MODERATE & $\begin{array}{l}\text { Determining construction costs based on similar } \\
\text { facilities and equipment on the basis of received } \\
\text { tenders. }\end{array}$ \\
\hline $\begin{array}{l}\text { Exceeding the operating } \\
\text { costs }\end{array}$ & B & $\mathrm{V}$ & HIGH & $\begin{array}{l}\text { Operating costs are compared with the costs for } \\
\text { similar projects in the similar period of time. }\end{array}$ \\
\hline $\begin{array}{l}\text { Problems with obtaining } \\
\text { grants }\end{array}$ & $\mathrm{C}$ & IV & HIGH & Employment of specialists to prepare a motion \\
\hline $\begin{array}{c}\text { Revenue lower than } \\
\text { expected }\end{array}$ & B & $\mathrm{V}$ & HIGH & $\begin{array}{l}\text { Determining the initial price and the inclusion of } \\
\text { increasing operating costs and potential revenue. }\end{array}$ \\
\hline
\end{tabular}

Risk analysis revealed two risk factors which have a very large impact on the investment. The first are delays in the schedule, which have impact on the subsidies from the EU, because any delay would cause a total loss of the funds and delays in putting the facility into service, thus, contributes to not meet environmental standards, and to impose financial penalties. Another threat are community protests and because Poland is country where environmental awareness is still being created, lack of information, can block the formation of incineration plant. Also five other factors of high risk were distinguished, which already were indicated at the stage of sensitivity analyzes. Other factors have been classified as moderate risk, which, should be monitored. In the table is not taken into account factors such as exceeding environmental standards or purchase of plot, as the project foresees the use of best available techniques, and the building plot, which was owned by the city, so the risk in their case would be sclassified as low, which does not mean that they should be completely ignored. Applied preventive measures should ensure decrease the risk to an acceptable level (moderate risk).

\section{Conclusions}

The analysis showed that the investment, which was a waste incineration plant in Cracow, from the very beginning was a complex investment burdened with considerable risks. This is the main reason why the decision on its implementation cannot be taken 
lightly, on the basis of taking into account only the economic or social issues. It was necessary to look at the investment comprehensively, considering not only the general benefits and also subsequent duties which are imposed on the owner of the object. Although the data used in the calculations were of a general nature, they allowed to illustrate the factors on which the project is particularly vulnerable, and qualitative risk assessment completed the financial analysis. Initially, taking into account only the economic aspects, the investment should not be taken into consideration at all. It should be remembered that this kind of investment, belongs to the municipal infrastructure, which do not generate enough income to be able to earn. In such cases, owner should ensure its financial sustainability. Due to the fact, that analysis showed that the factors of high risk are expected amount incurred operating costs and revenues, special attention should be paid to their forecasting eg. the rising costs of facility maintenance. But especially important aspect is the satisfaction of the public, who is pleased that the city will become more ecological, but it would be the best if the plant was built as far from their properties as possible, therefore, great importance should be given to public consultation, during which, in addition to the measurable benefits can be point out, these overlooked and overshadowed by a vicious stereotypes, such as the creation of new jobs and creating additional source of heat, extension of the operation time of the landfill Barycz, the aesthetics of the object itself as opposed to landfill, thriftiness of plot area - incinerator needs about 10 times less hectares than landfill, reducing methane emissions and a smaller decrease in property prices than in the case of construction of the landfill. Despite all possible aspects, despite the high risks and difficulties that could encounter project - decided to counteract the difficulties associated with the construction of incinerators.

\section{References}

1. B.Tchórzewska-Cieślak, J.R. Rak, K. Pietrucha, JPSRA SSARS, 1, 185-195 (2011)

2. http://eur-lex.europa.eu/legal-content/en/TXT/?uri=CELEX:32008L0098

3. E. Georgopoulou, V. Hontou, N. Gakis, Y. Sarafidis, S. Mirasgedis, D.P. Lalas, A. Loukatos, N. Gargoulas, A. Mentzis, D. Economidis, T. Triantafilopoulos, K. Korizi, J Clean Prod, 6(3), 359-373 (2008)

4. Ocena strategiczna Systemu Gospodarki Odpadami Miasta Krakowa wraz z wyborem wariantów lokalizacji zakładu termicznego przekształcania odpadów komunalnych, 2007 (not published, released excerpts)

5. K. Govindan, S. Rajendran, J. P.Sarkis, P. Murugesan, J Clean Prod, 98(1), 66-83 (2015)

6. C. Kahraman, Springer Optim Appl, 16, 1-18 (2008)

7. A. Generowicz, Z. Kowalski, M. Banach, A. Makara, Waste Manage, 32, 349-351(2012)

8. J. Rak, Polska Inżynieria Środowiska - Prace, 209-2017 (2012)

9. https://www.mos.gov.pl/fileadmin/user_upload/fundusze/Przewodnik_do_analizy_kos ztow.pdf

10. H. Hu, X. Li, A. Dung Nguyen, P. Kavan, Int J Environ Res Publ Health, 12, 7593-7614 (2015)

11. http://www.abcm.org.br/anais/encit/2010/PDF/ENC10-0663.pdf

12. S. Udomsri, A. R. Martin, T. H. Fransson, Waste Manage, 30, 1414-1422 (2010)

13. A. Generowicz, J. Kulczycka, Z. Kowalski, M. Banach, J Environ Manage, 92(4), 1314-1320 (2011). 